\title{
A Climatology of Cold-Season Nonconvective Wind Events in the Great Lakes Region
}

\author{
Matthew C. Lacke,*,\& John A. Knox, ${ }^{+}$John D. Frye,* Alan E. Stewart, ${ }^{\#}$ Joshua D. Durkee,* \\ Christopher M. Fuhrmann, ${ }^{@}$ And SARAh M. Dillingham* \\ * Department of Geography, The University of Georgia, Athens, Georgia \\ + Faculty of Engineering, The University of Georgia, Athens, Georgia \\ \# Department of Counseling and Human Development, The University of Georgia, Athens, Georgia \\ @ Department of Geography, University of North Carolina at Chapel Hill, Chapel Hill, North Carolina
}

(Manuscript received 27 October 2006, in final form 10 April 2007)

\begin{abstract}
A 44-yr climatology of nonconvective wind events (NCWEs) for the Great Lakes region has been created using hourly wind data for 38 first-order weather stations during the months of November through April. The data were analyzed in terms of the two National Weather Service (NWS) criteria for a high-wind watch or warning: sustained winds of at least $18 \mathrm{~m} \mathrm{~s}^{-1}$ for at least $1 \mathrm{~h}$ or a wind gust of at least $26 \mathrm{~m} \mathrm{~s}^{-1}$ for any duration. The results indicate a pronounced southwest quadrant directional preference for nonconvective high winds in this region. Between $70 \%$ and $76 \%$ of all occurrences that satisfied the NWS criteria for NCWEs were associated with wind directions from $180^{\circ}$ through $270^{\circ}$. Within the southwest quadrant, the west-southwest direction is preferred, with $14 \%-35 \%$ of all NCWEs coming from this particular compass heading. This directional preference is borne out in five out of six stations with high occurrences of cold-season NCWEs (Buffalo, New York; Dayton, Ohio; Lansing, Michigan; Moline, Illinois; Springfield, Illinois). Given the geographic spread of these stations, a nontopographic cause for the directional preference of cold-season NCWEs is indicated. The connection between NCWEs and low pressure systems found in this climatology and in case studies suggests that midlatitude cyclone dynamics may be a possible cause of the directional preference.
\end{abstract}

\section{Introduction}

A nonconvective wind event (NCWE) is defined in this paper as any nonthunderstorm wind that meets the National Weather Service (NWS) criteria (http://www. weather.gov/glossary) for a high-wind watch and warning (i.e., sustained winds of $18 \mathrm{~m} \mathrm{~s}^{-1}$ or $40 \mathrm{mph}$ for at least $1 \mathrm{~h}$; or a gust of $26 \mathrm{~m} \mathrm{~s}^{-1}$ or $58 \mathrm{mph}$ for any duration). We will refer to the sustained-wind threshold as "criterion A" and the wind-gust threshold as "criterion B." These wind speed thresholds exceed the minimum wind speed of tropical storms $\left(17 \mathrm{~m} \mathrm{~s}^{-1}\right)$, as well as match severe weather criteria (i.e., wind gust greater than or equal to $26 \mathrm{~m} \mathrm{~s}^{-1}$ ).

\& Current affiliation: Air and Radiation Protection Division, Jefferson County Department of Health, Birmingham, Alabama.

Corresponding author address: Dr. John A. Knox, Faculty of Engineering, University of Georgia, Driftmier Engineering Center, Athens, GA 30602.

E-mail: jknox@engr.uga.edu

DOI: 10.1175/2007JCLI1750.1

(C) 2007 American Meteorological Society
NCWEs can produce considerable socioeconomic impacts including downed trees and power lines, property and crop damage, travel delays, injuries, and casualties. The annual Summary of Natural Hazard Statistics for 2000-04 (Table 1) depicts damages, injuries, and deaths associated with wind events (http://www. weather.gov/os/hazstats.shtml). Over the period of 2000-04, high winds (an NWS category that includes NCWEs) were responsible for approximately the same number of deaths as those that resulted from tropical cyclones. In addition, high winds caused more propertyand crop-related damages than did winds produced by either convective storms or tornadoes from 2000 to 2004.

NCWEs play a particularly important role in the Great Lakes region. NCWEs have been responsible for $21 \%$ of weather-related deaths and property damage events exceeding \$0.5 million in the Great Lakes region from 1960 to 1985 during the fall season, and $28 \%$ of such events in the winter season (Niziol and Paone 2000).

Several studies have addressed the synoptic and dynamic aspects of NCWEs in specific case studies (e.g., Pauley et al. 1996; Iacopelli and Knox 2001; Browning 
TABLE 1. Cumulative 2000-04 weather hazard statistics for the United States from the annual Summary of Natural Hazard Statistics (http://www.weather.gov/os/hazstats.shtml).

\begin{tabular}{lccc}
\hline \multicolumn{1}{c}{ Wind event } & Deaths & Injuries & Damage $(\$ \mathbf{M})$ \\
\hline High wind & 118 & 613 & 4093.0 \\
Thunderstorm wind & 94 & 1394 & 1632.5 \\
Tornado & 225 & 4076 & 3700.8 \\
Tropical cyclone & 123 & 1427 & 28070.5 \\
\hline
\end{tabular}

2004; Crupi 2004; Knox and Schmidt 2005; Hultquist et al. 2006; Durkee et al. 2007, unpublished manuscript). However, very little is known about the climatology of damaging nonconvective winds. One exception is the study by Niziol and Paone (2000), who created a climatology of NCWEs based on criterion B for Buffalo, New York, from 1977 to 1997. The authors observed that NCWEs 1) predominantly occurred from October through April, 2) had prevailing wind directions from southwest to west, and 3) occurred in the southwest quadrant of a midlatitude cyclone in the wake of a coldfrontal passage and in a region of synoptic-scale subsidence. Niziol and Paone's climatology does not address the ultimate causes of the NCWEs in Buffalo; however, the authors do address a possible meteorological factor and explain that southwest winds may be channeled toward Buffalo because of its location at the narrowing eastern end of Lake Erie. Otherwise, the literature on wind in the Great Lakes region is surprisingly sparse and is limited mostly to wind-energyrelated analyses. One exception is Klink (2002), who examined near-surface wind speed variability at seven stations in and surrounding Minnesota.

The current study (see also Knox 2004) seeks to advance our understanding of NCWEs by examining coldseason (defined here as November through April) events across the Great Lakes region from 1951 to 1995. By focusing upon the Great Lakes region, it is possible to include many NCWEs because this is a region that has historically experienced many such events, especially during the winter months, such as the Great Lakes Storm of 1913 and the Armistice Day and Edmund Fitzgerald storms of 1940 and 1975, respectively (e.g., Richwien 1980). A 44-yr sample of NCWEs produces robust estimates of meteorological variables that are relevant to these events, such as pressure, sustained winds, and wind directions of sustained and gust winds.

\section{Data and methods}

Hourly wind and sea level pressure data were extracted from Climate Data Online (CDO) provided by the National Climatic Data Center (NCDC; http://cdo.
ncdc.noaa.gov/CDO/cdo). The data consist of qualitycontrolled, decoded aviation routine weather reports (METAR) for 38 NWS first-order weather stations throughout the Midwest and Great Lakes region (Fig. 1) for the cold seasons of 1951-95. These stations were chosen because they closely delineated the area studied by Angel and Isard (1998) with respect to the frequency of Great Lakes cyclones.

A period of record of 1951-95 was used in this study for two reasons. First, 1995 was chosen as the end point of the data range because this year marked the transition from human observers to the widespread deployment of automated surface observing stations across the United States. Second, the 44-yr period of record permitted the maximum possible number of observing stations (i.e., 38) to be included in the analysis.

One small drawback of the NCDC CDO archive is nonarchived and missing data. Only 3-hourly reports are archived for most stations during a subset of the years 1965-73. In addition, missing data were noted at four of the stations chosen for the study. Rockford, Illinois, and Lansing, Michigan, data are missing for the periods January 1955-October 1958 and January 1955April 1959, respectively. Dubuque, Iowa, data are missing for January 1951 and contain roughly one-third fewer observations than other first-order stations from the 1950s until the mid-1970s. Waterloo, Iowa, data are missing for January and February of 1960 . However, the missing data at these four stations represent no more than about $2.5 \%$ of the more than six million hourly wind observations collected at the 38 stations during the cold seasons of 1951-95 and do not appear to affect the conclusions of this study. In addition, no wind-gust data prior to 1974 is available in the NCDC $\mathrm{CDO}$ for the stations analyzed. Although this is a drawback in terms of total amount of data, it also has the advantage of reducing concerns with regard to changes in anemometer height at many stations (see the discussion section).

The authors took steps to ensure that the wind events analyzed in this study were associated with nonconvective weather. Only the months of November through April were used because convective events are rare in the Great Lakes region during the cold season. The study also included only those observations with no indication of convective storms in the "present weather" data field.

Wind data were subdivided according to the two NWS high-wind warning criteria. There are some ambiguities in how best to identify occurrences of high winds from the NCDC CDO database. For example, the official definition of criterion A requires at least $1 \mathrm{~h}$ of winds at or above $18 \mathrm{~m} \mathrm{~s}^{-1}$. This is not the same as a 


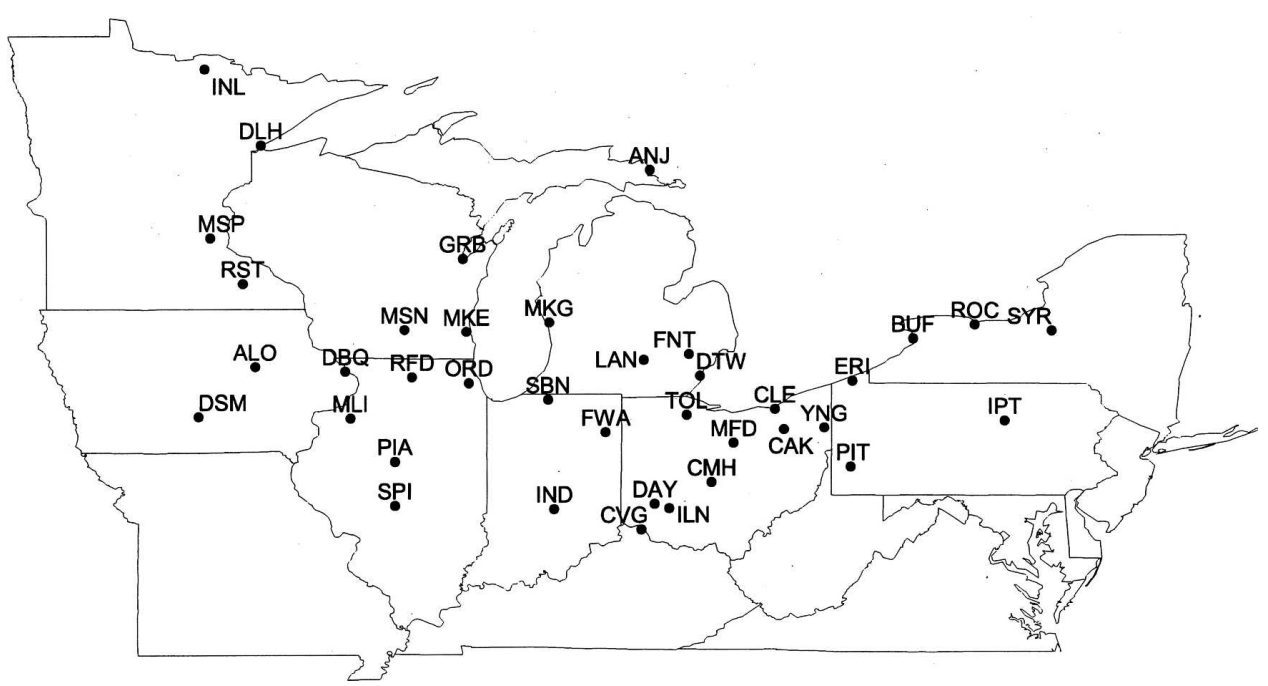

FIG. 1. The 38 first-order station network used to create a climatology of NCWEs in the Great Lakes region during the cold season (November-April) for the period 1951-95.

2-min average wind speed, which is how sustained winds are recorded (e.g., chapter 5 in http://www.ofcm. gov/fmh-1/pdf/FMH1.pdf). However, to our knowledge no hourly averaged wind climatology exists that would conform to the NWS definition. Furthermore, the NWS definition itself is not set in stone. Some NWS offices have lower local criteria for high wind events (S. Nelson, Science Operations Officer, NWS WFO Peachtree City, Georgia, 2007, personal communication). To strike a compromise between definitions and data availability, on the advice of National Weather Service personnel we chose to define 1-hourly occurrence of sustained winds at or above $18 \mathrm{~m} \mathrm{~s}^{-1}$ as satisfying criterion A. While this compromise may overestimate the number of criterion-A NCWE occurrences, we believe that it is the best option and is far preferable to omitting the analysis of sustained winds.

In the case of criterion $\mathrm{B}$, we used wind-gust data rather than peak wind speed data. The NCDC CDO database contained little peak wind information. In addition, Niziol and Paone (2000) also used wind-gust data rather than peak wind speed data in their analysis. Therefore, for reasons of data availability and consistency with past research we chose to use wind-gust data. This choice likely underestimates the occurrences of criterion-B NCWEs, but again is the best option given data availability.

Observations of mean sea level pressure, wind speed, and wind direction were recorded for each NCWE. Wind roses were created for six stations: Buffalo, New York (BUF); Dayton, Ohio (DAY); Lansing, Michigan (LAN); Moline, Illinois (MLI); Rochester, Minnesota
(RST); and Springfield, Illinois (SPI). These stations were chosen because they had the highest occurrence of NCWEs in both wind categories. In addition, the choice of these stations provided an indication of how wind directions were typically distributed throughout the study area. There were a few stations with a high number of events (e.g., Erie, Pennsylvania) that were not examined in detail because of their proximity to one of the six stations chosen for closer examination (e.g., Buffalo, New York).

\section{Results}

\section{a. Overview}

During the cold seasons of 1951-95, the 38 first-order Great Lakes region stations recorded 2336 observations that satisfied the sustained-high-wind criterion A. These observations represent approximately $0.04 \%$ of the over six million hourly sustained-wind observations at these stations for this period. A total of 239 observations satisfied the high-wind-gust criterion B. As is shown below, these events were not distributed equally in space or time, but did span all cold-season months and the entire geographic extent of the Great Lakes region.

\section{b. NCWE frequency by month}

Approximately one-half of all events satisfying criterion A occurred in the months of March and April (Fig. $2 a)$. March (27\%) had the highest frequency of this type of NCWE. Slightly different results were observed for events with criterion B (Fig. 2b) in that most events 


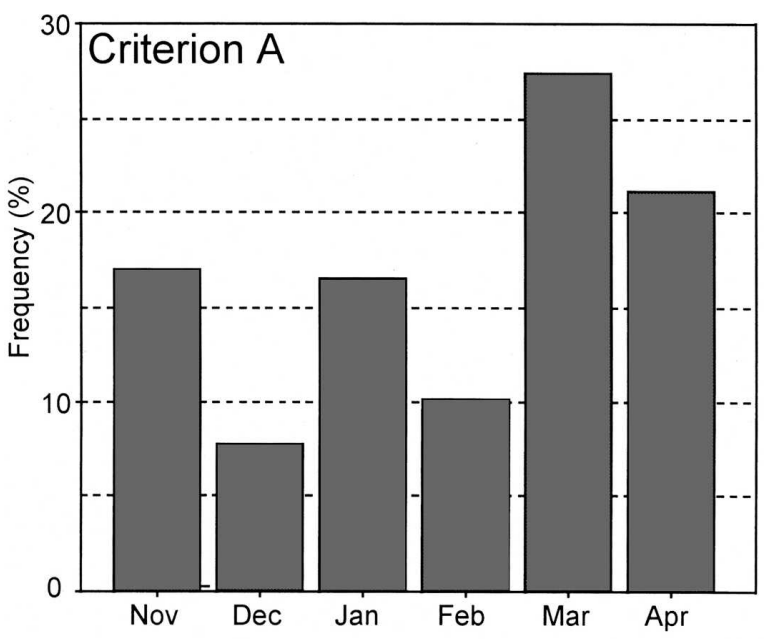

(a)

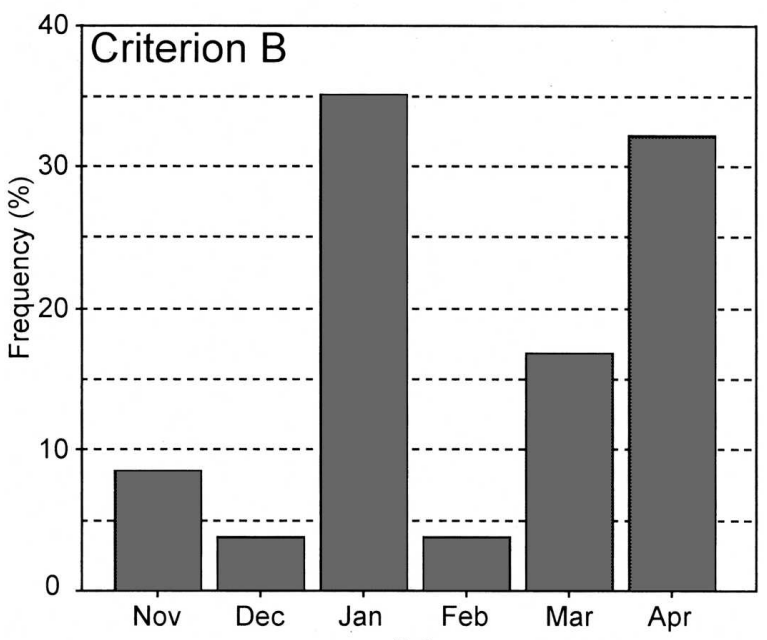

(b)

FIG. 2. The frequency of wind observations in percent by month for observations satisfying (a) criterion A and (b) criterion B.

occurred in the months of January (35\%) and April $(32 \%)$.

\section{c. NCWE frequency by location}

Data from each of the 38 first-order stations were analyzed to determine the climatology of criterion A. Figures $3 \mathrm{a}$ and $3 \mathrm{~b}$ are graduated circles maps of the number of these events observed at each station. In events that met criterion A or criterion B, they most commonly occurred at stations along Lake Erie, Lake Ontario, and the western part of the Midwest.

\section{d. Sea level pressure}

Sea level pressures observed during NCWEs were examined to determine the typical values and ranges of pressure for the two categories of NCWEs. For events satisfying criterion A, there were 2018 observations that also reported sea level pressure. From this sample, a median sea level pressure of $1000.8 \mathrm{hPa}$ was calculated. The lowest pressure with sustained nonconvective high winds was $959.6 \mathrm{hPa}$ and the highest pressure was $1035 \mathrm{hPa}$. This result suggests that NCWEs can be associated with both high and low pressure systems, but there is a preference for lower pressures since the median is well below average sea level pressure. For NCWEs satisfying criterion B, 185 of those observations that also reported sea level pressure had a median pressure of $993.5 \mathrm{hPa}$. The lowest sea level pressure recorded was $967.1 \mathrm{hPa}$ and the highest was $1016.7 \mathrm{hPa}$. The median pressure was more than $7 \mathrm{hPa}$ lower than what was found with criterion-A events; the maximum pressure was more than $28 \mathrm{hPa}$ lower than the maximum occurring with criterion-A events.

An independent samples $t$ test was conducted to see if there was a significant difference in sea level pressure between the two criteria. A $t$ value of 9.9 was found at a $99 \%$ confidence level, demonstrating that there is a significant difference between pressures observed for the two NWS high-wind watch and warning criteria. In short, high wind speeds were generally associated with low sea level pressures, and the highest gusts were generally associated with the lowest sea level pressures.

\section{e. Wind direction}

A persistent directional preference for NCWEs was discovered across the entire Great Lakes region. The vast majority of NCWEs in the dataset occurred with winds from the southwest quadrant $\left(180^{\circ}-270^{\circ}\right)$. For NCWEs satisfying criterion A, $70 \%$ of the events occurred with southwest quadrant winds (Fig. 4a). Specifically within the southwest quadrant, the west-southwest direction was the most common, accounting for nearly $14 \%$ of the events. NCWEs with winds from the other quadrants, while present, were noticeably less frequent. Figure $4 \mathrm{~b}$ shows that about $76 \%$ of all events satisfying criterion B occurred in the southwest quadrant. The most common wind direction was from the west-southwest and occurred approximately $35 \%$ of the time during these events. (The zero frequencies in Fig. $4 \mathrm{~b}$ occurred because wind-gust reports were rounded in the NCDC data to the nearest $10^{\circ}$.) In summary, both types of NCWEs were associated primarily with southwest quadrant winds, and a plurality of events emanated from just one compass heading: west-southwest.

\section{f. Wind direction analyses for selected cities}

To explore the wind direction results in more detail, wind roses were created for six cities around the Great 


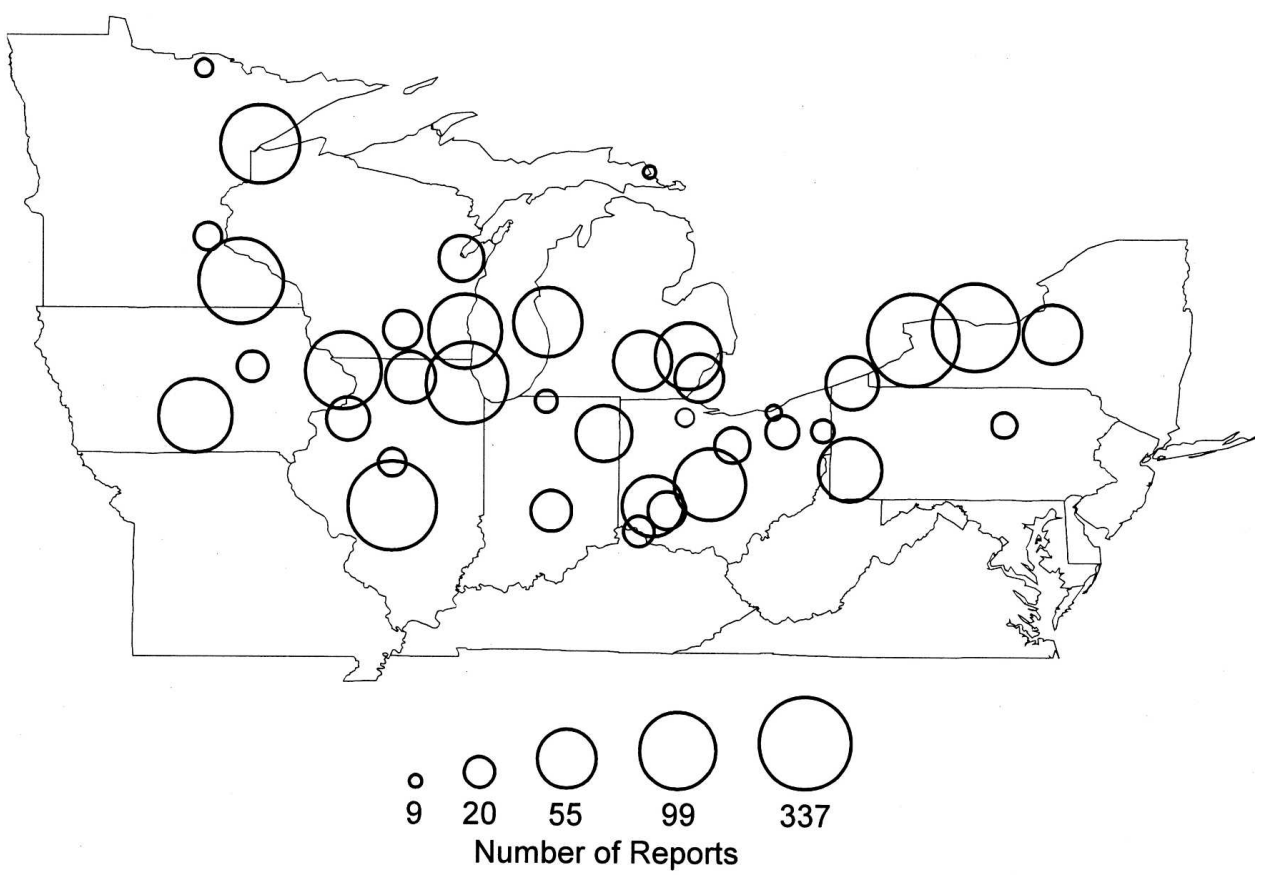

(a)

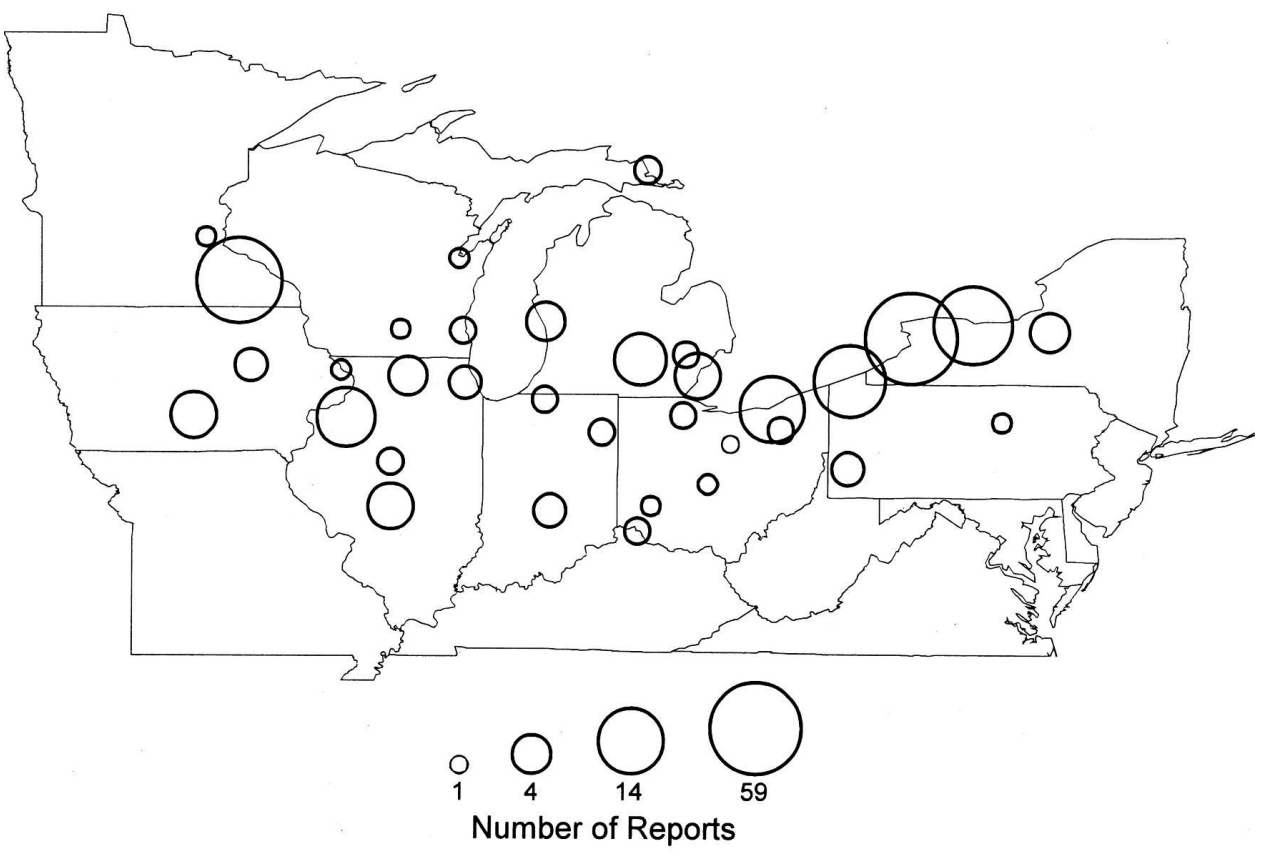

(b)

FIG. 3. Graduated circle maps indicating the number of reports of NCWEs associated with (a) criterion A and (b) criterion B.

Lakes region. Wind roses were prepared for BUF, LAN, MLI, DAY, SPI, and RST and appear in Figs. $5-10$, respectively. These stations were chosen because they had among the highest occurrences of NCWEs for all criteria among the 38 stations in the dataset. The results for some stations on the fringes of the Great Lakes region differ in some respects from those in the center of the region; however, a regionwide pattern is evident.

For each city, three wind roses depict (i) the wind 


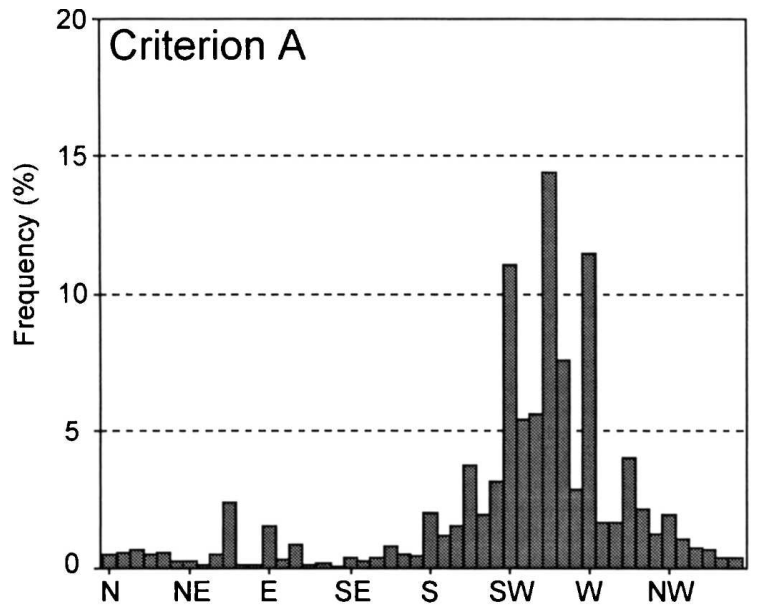

(a)

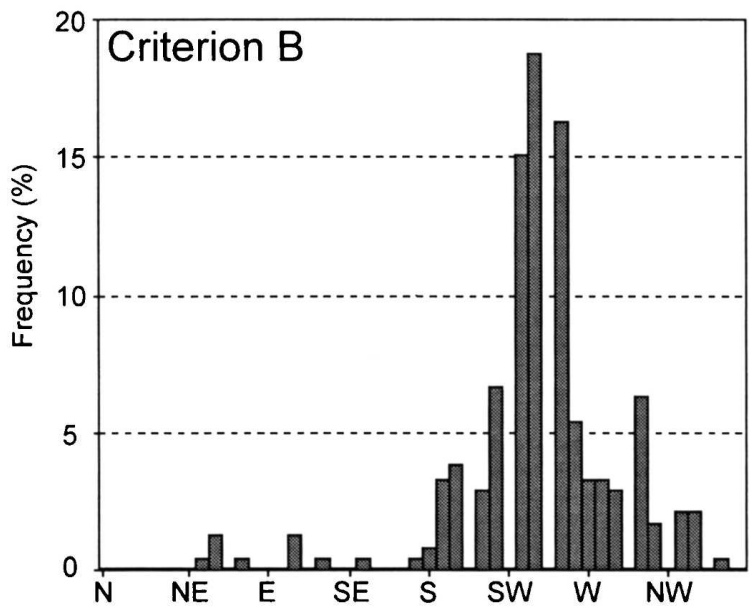

(b)

FIG. 4. The frequency of wind observations in percent by cardinal direction for observations satisfying (a) criterion A and (b) criterion B.

directions for all wind reports for the entire 44-yr coldseason period of record (POR), (ii) wind directions observed for events satisfying criterion A, and (iii) wind directions observed for events satisfying criterion B.

Five out of the six stations exhibited preferred NCWE wind directions from the southwest quadrant, in agreement with the regional climatology. In some locations this directional preference of NCWEs was the same as for all winds; in others, NCWEs came from a wind direction that is comparatively rare for the entire POR.

For the POR in BUF, the most commonly occurring wind directions were southwest and west (Fig. 5a). A similar pattern was found for all NCWEs at BUF, regardless of wind intensity (Figs. 5b and 5c). The wind roses for LAN and MLI revealed greater variability in

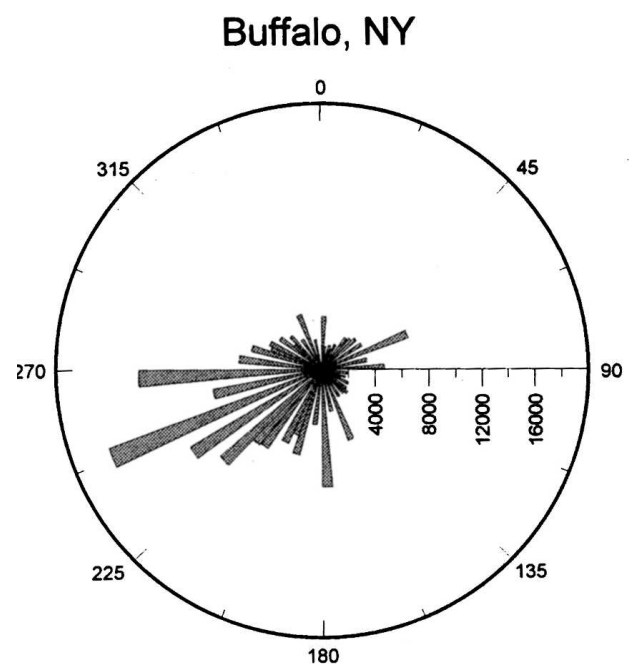

(a)

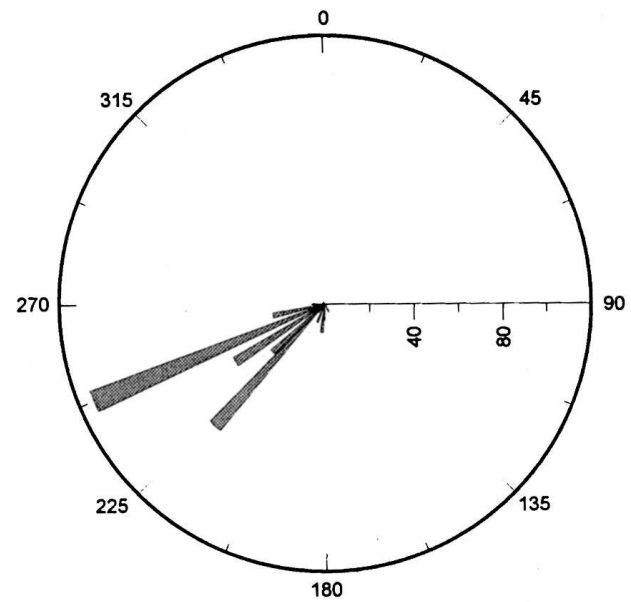

(b)

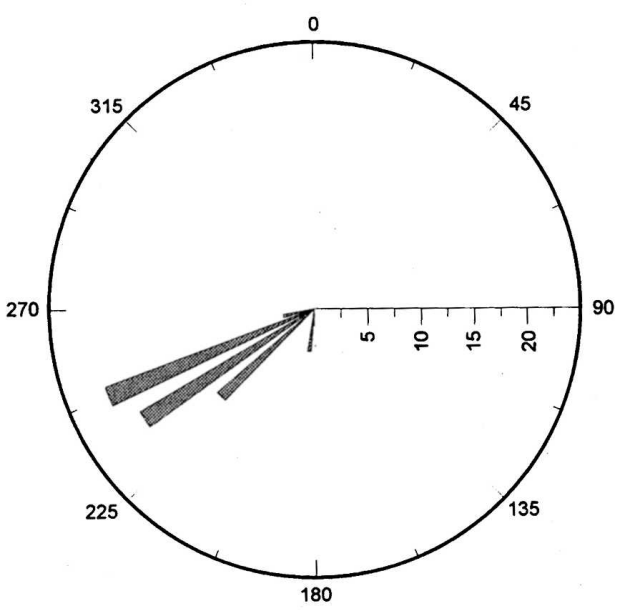

(c)

FIG. 5. Wind rose for Buffalo, NY, which indicates the frequency of wind observations along the inner line and the wind direction in degrees on the outside of the circle for (a) the POR, (b) those satisfying criterion A, and (c) those satisfying criterion $\mathrm{B}$. 
comparison to BUF. For the POR, the dominant wind directions for LAN were from the south and west (Fig. $6 a)$. The wind rose for LAN showed that NCWEs satisfying criterion A were predominantly from a westerly direction (Fig. 6b). However, NCWEs achieving criterion-B thresholds at LAN showed a west-southwest direction (Fig. 6c). The dominant direction was west for the POR for MLI (Fig. 7a), with the most frequent directions being the west-southwest and west for NCWEs (Figs. 7b and 7c). BUF, LAN, and MLI were similar in that the directions associated with NCWEs, regardless of magnitude, were consistent with the prevailing wind direction throughout the entire POR.

The analyses for DAY and SPI, on the southern fringe of the Great Lakes region, revealed a somewhat different relationship between the POR wind directions and the directions associated with NCWEs. The wind rose for DAY showed that for all wind observations a southerly direction was the most common (Fig. 8a). NCWE wind directions, however, were predominantly from the west and west-southwest (Figs. $8 \mathrm{~b}$ and 8c). The POR winds for SPI exhibited a southerly component (Fig. 9a). The pattern of NCWE directions at SPI, however, was mostly from the west for criterion-A events (Fig. 9b). Winds satisfying criterion B possessed more variable southwesterly components (Fig. 9c).

The wind roses for RST, on the western edge of the Great Lakes region, also exhibited a different relationship between the POR wind directions and the directions associated with NCWEs. The southerly direction was the most common for the POR (Fig. 10a). Wind directions for NCWEs, however, were predominantly from the west-northwest at RST (Figs. 10b and 10c). RST is the only one of the six stations to exhibit a persistent pattern of non-southwest-quadrant NCWEs.

In summary, five of the six stations with high occurrences of NCWEs confirm the southwest quadrant preference for NCWEs across the Great Lakes region.

\section{Discussion}

This new climatology of nonconvective wind events has revealed that southwest $\left(180^{\circ}-270^{\circ}\right)$ wind directions occurred in $70 \%$ and $76 \%$ of Great Lakes region NCWEs associated with National Weather Service high-wind criteria A and B, respectively.

These results are robust not only over time and space, but also with respect to changes in wind observation measurements. On the suggestion of a reviewer, the Local Climatological Data (LCD) annual summary for each station in this study was examined to see if there were significant changes in the height of wind measurements. In the 1950s and early 1960s, anemom-

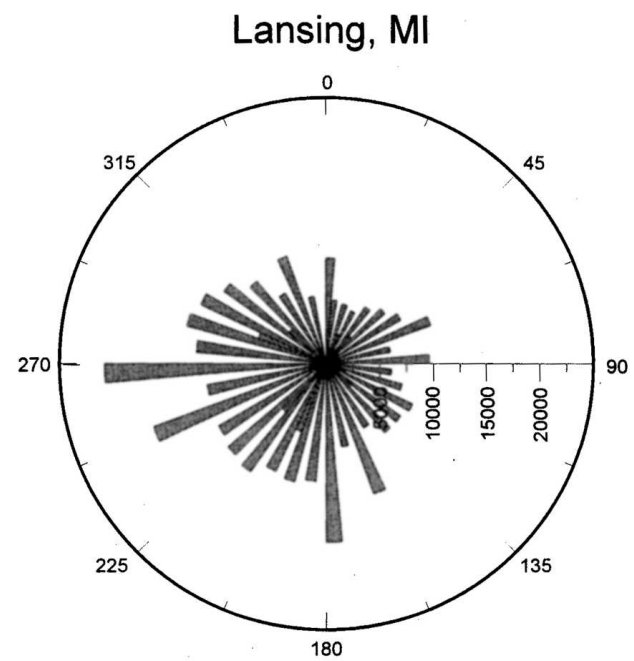

(a)

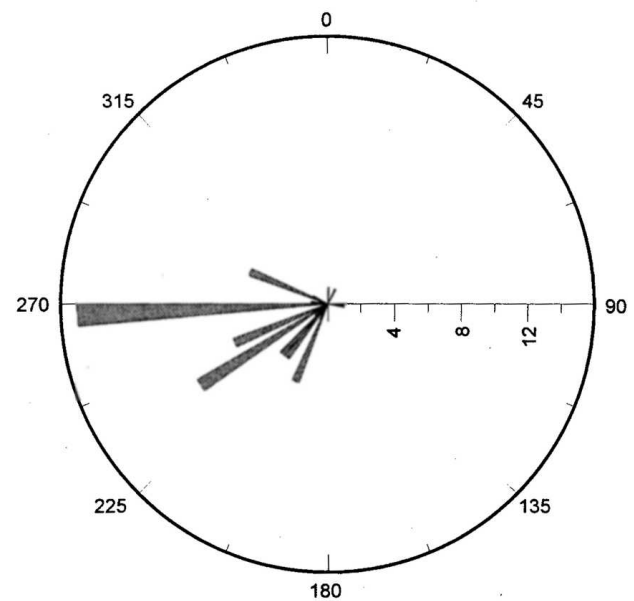

(b)

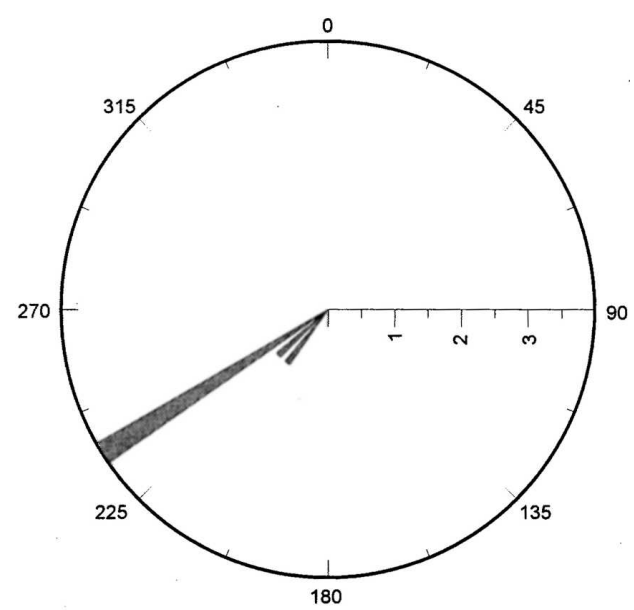

(c)

FIG. 6. Same as in Fig. 5, but for Lansing, MI. 




(a)

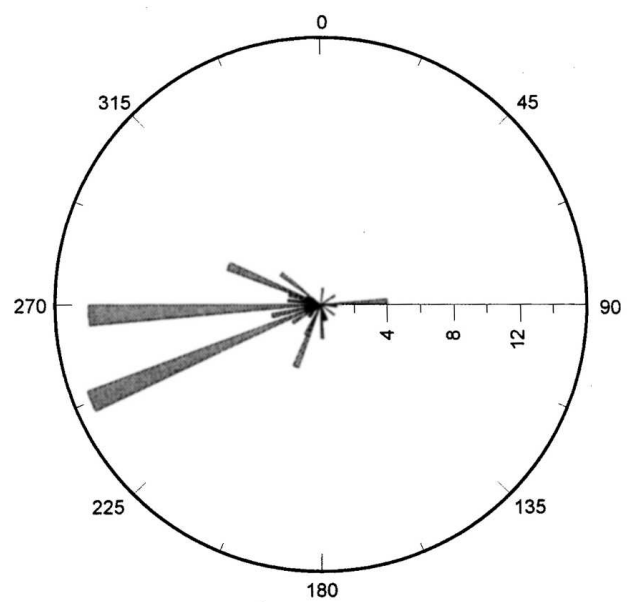

(b)

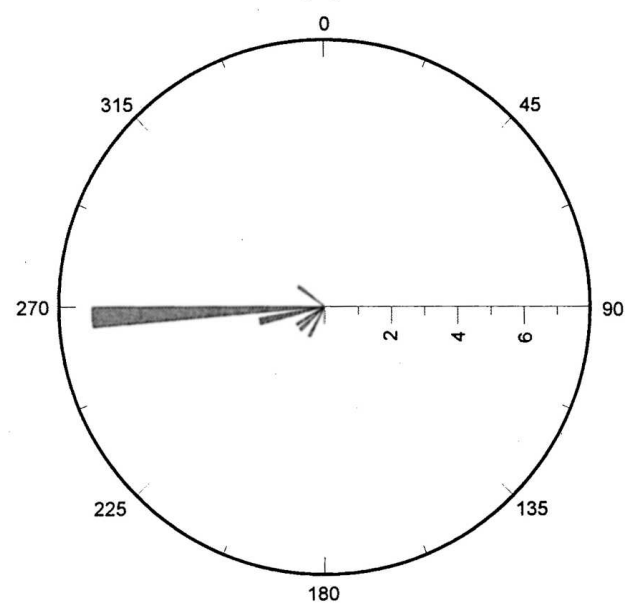

(c)

FIG. 7. Same as in Fig. 5, but for Moline, IL.

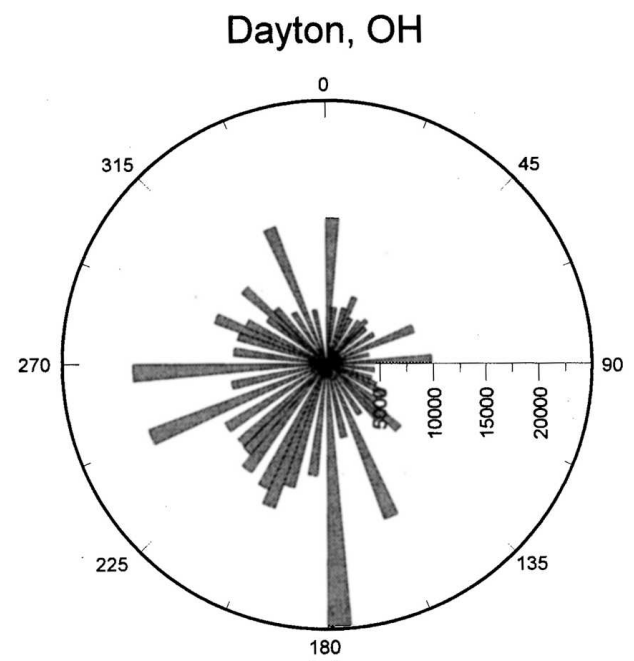

(a)

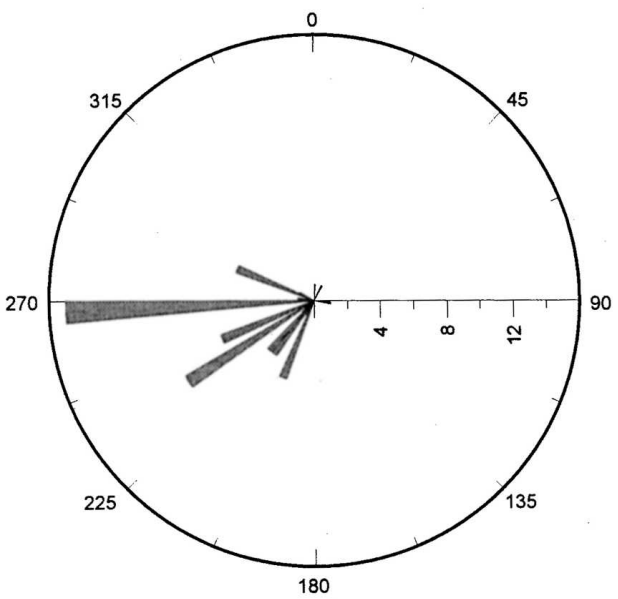

(b)

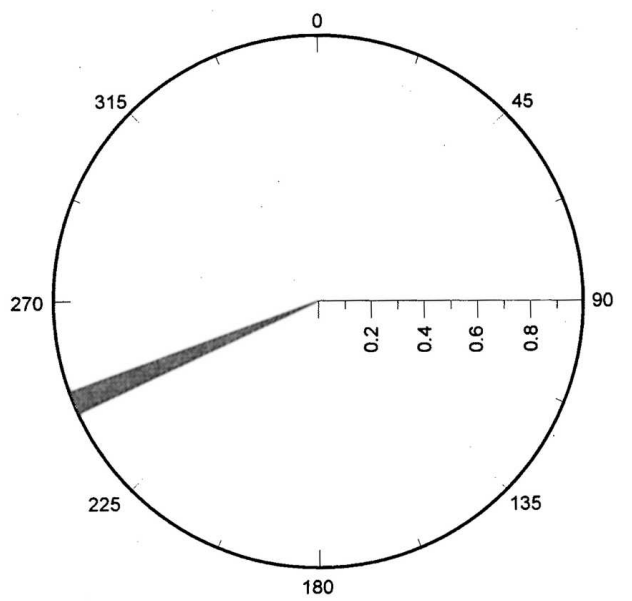

(c)

FIG. 8. Same as in Fig. 5, but for Dayton, OH. 
Springfield, IL

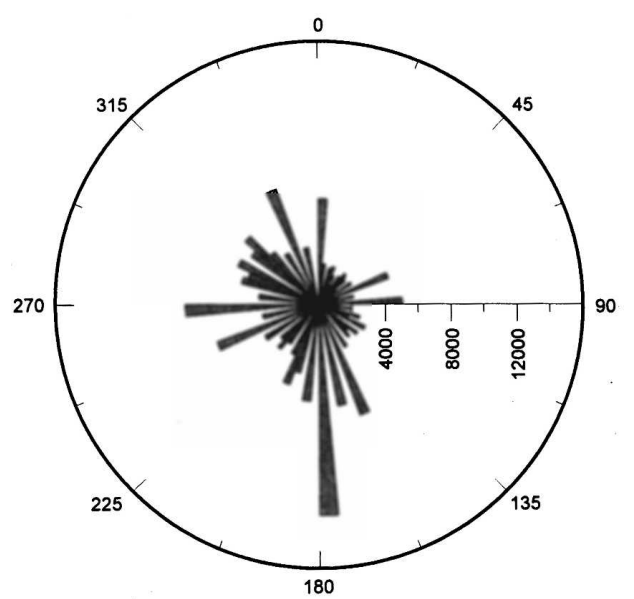

(a)



(b)

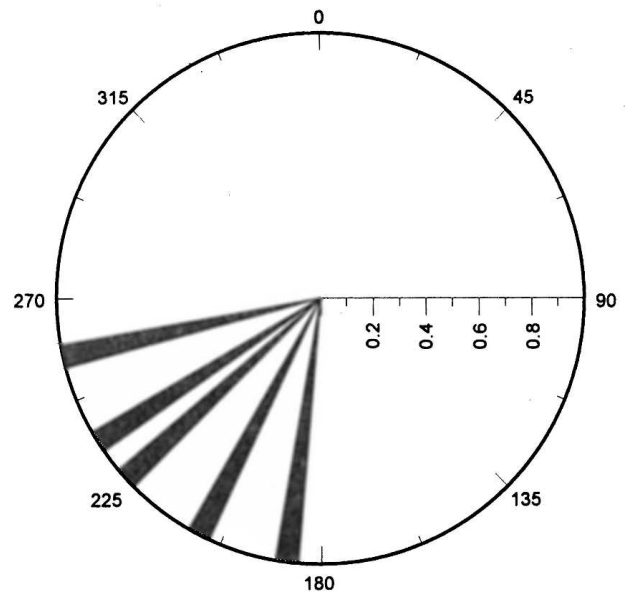

(c)

FIG. 9. Same as in Fig. 5, but for Springfield, IL.

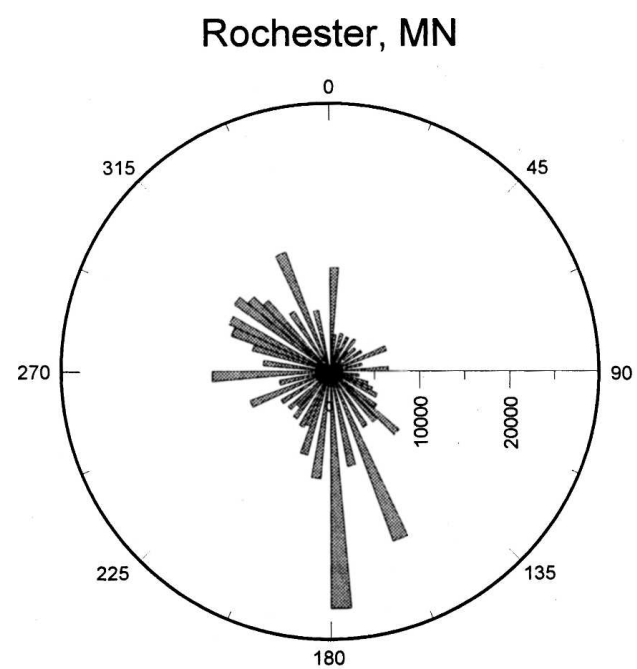

(a)

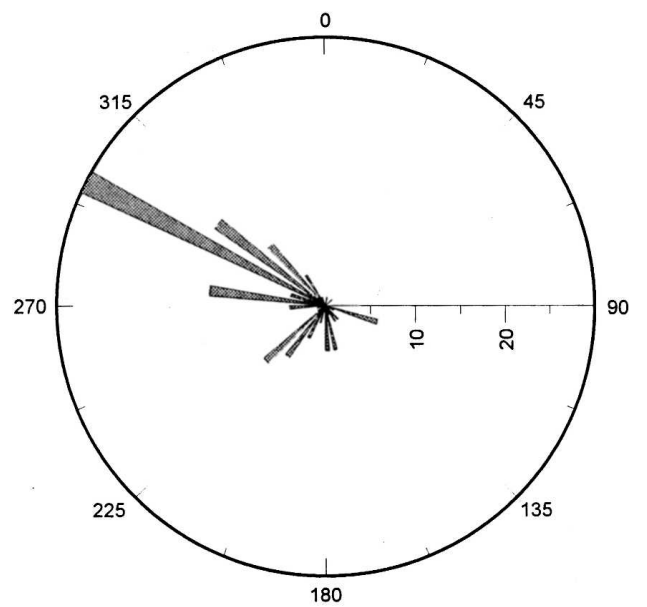

(b)



(c)

FIG. 10. Same as in Fig. 5, but for Rochester, MN. 


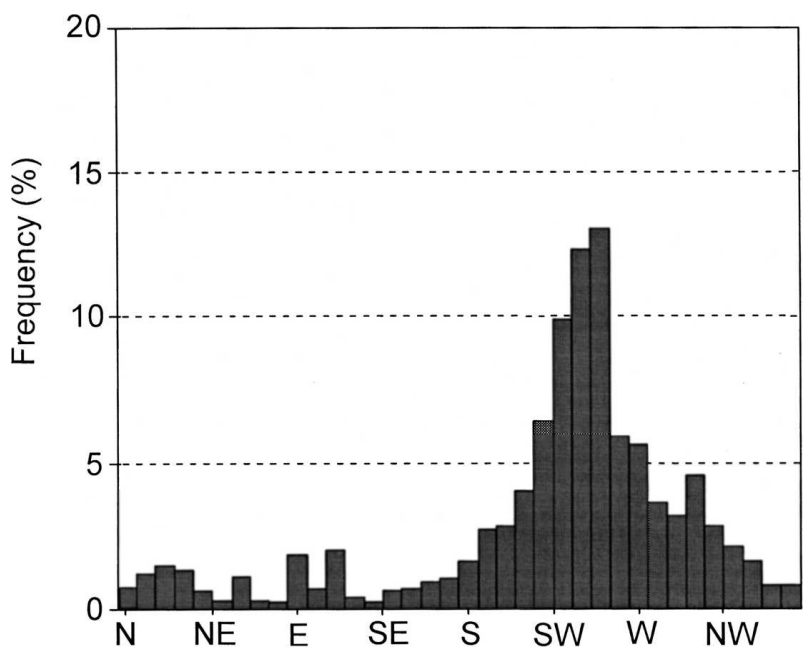

FIG. 11. The frequency of wind observations in percent by cardinal direction for observations satisfying criterion A for the period 1967-95, during which anemometer elevations across the Great Lakes region were equal to or less than $10 \mathrm{~m}$ (cf. to Fig. 4a).

eter heights were not standardized and were often 12

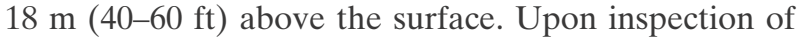
the LCDs, it was determined that wind observations at all stations in this study were reduced to lower heights (10 $\mathrm{m}$ or less) by 1967 . The climatology was then reanalyzed for the period 1967-95, which included 981 occurrences satisfying criterion A ( $42 \%$ of the total for the POR). The results, as seen in Fig. 11, are virtually identical to the full POR (cf. Fig. 4a). Since wind-gust data in the NCDC CDO begin in 1974, changes in anemometer heights during the 1950s and early 1960s did not affect our results for criterion B.

These results are also consistent with the results of Niziol and Paone (2000) for Buffalo. Furthermore, our results significantly extend Niziol and Paone's results in both space and time and raise the following question: What causes this persistent, widespread preference for certain wind directions for NCWEs?

Niziol and Paone (2000) stated that geographical features (i.e., Lake Erie) might have been a dominating influence on the direction of NCWEs in Buffalo. The present study suggests a more general meteorological cause, because the pattern seen in Buffalo is also widespread and persistent across the Great Lakes region.

Our analysis of sea level pressure indicates that NCWEs are usually associated with low pressure; furthermore, the highest nonconvective wind gusts are linked to the lowest pressures. Although NCWEs could also be associated with strong pressure gradients associated with intense anticyclones, high-pressure NCWEs are rare in our climatology. These results are noteworthy because they imply that most cold-season NCWEs may be associated with midlatitude cyclones. While individual case studies have linked nonconvective high winds with midlatitude cyclones, this is to our knowledge the first study to imply a regionwide climatological connection between NCWEs and midlatitude cyclones. [As noted above, Niziol and Paone's (2000) work was limited to western New York state, as proxied by data at only one site.] Therefore, we hypothesize that the southwest quadrant wind preference during NCWEs is associated with midlatitude cyclone dynamics. We explore this hypothesis in greater detail elsewhere.

The connection between NCWEs and midlatitude cyclone dynamics is further reinforced by the wind roses for RST. Our analysis of RST winds indicated a preference for the direction of NCWEs at that station to be from a west-northwest direction. The location of RST relative to cold-season midlatitude cyclone paths across the Midwest could explain the dissimilarity in the direction of NCWEs at RST when compared to the other stations in the study area. Alone among the six stations examined, RST is located to the north and west of the persistent "Panhandle Hook" storm track (Whittaker and Horn 1982).

In addition, recent work by Martin and Konrad (2006), in a study of high wind gusts in the southeastern United States, reveals a predominant southwest-tonorthwest directional component across the Piedmont region. The authors attribute this pattern to the passage of midlatitude cyclones during the late winter and early spring. To explore this possibility, we are developing an integrated multiscale conceptual model of how midlatitude cyclones produce NCWEs, based on individual case studies (Durkee et al. 2007, unpublished manuscript).

A majority of the NCWEs in our study occurred in January, March and April. High-wind events occurred much less frequently in the months of November, December, and February. This result runs counter to anecdotal evidence and weather folklore that suggest "witch of November" storms are the most common source of cold-season NCWEs. It is possible that November NCWEs are more memorable because those that occur in the spring (i.e., in March and April) are thought to be associated with convective storms. That is, a severe windstorm in November may be more memorable than one that occurs during months that are ordinarily thought to herald the thunderstorms of spring. Alternatively, since November windstorms occur shortly after the early fall climatological mean minimum in wind speeds in the upper Midwest (Knox 1996), those storms may be more surprising and memorable than spring windstorms that follow the windy winter months. 
It would be of interest to compare our results to Angel and Isard's (1998) examination of trends in cyclone frequency and intensity. However, their nine-decade study permits much more confidence in long-term trends than our present study. For example, the increasing trend in strong Great Lakes cyclones found by Angel and Isard is counter to the trend of decreasing anemometer elevation during the first two decades of our study. Furthermore, the exact connection between cyclone intensity and NCWEs has not yet been established. As a result, this is left to future work.

Also left to future work is any attempt to standardize the NCDC CDO wind data with respect to anemometer height differences, surface roughness, obstacles and orography, as performed by Martin (2000) for the southeastern United States. While valuable, such work is beyond the scope of the present study, and-as shown above with respect to anemometer height changes-would not significantly alter the conclusions herein.

In summary, our work reveals for the first time a climatological pattern of southwest-quadrant nonconvective high winds during the cold season across the entire Great Lakes region, a pattern previously identified at only one station.

Acknowledgments. We gratefully acknowledge the suggestions of the anonymous reviewers, which significantly improved the manuscript. We thank Pam Knox, Tom Mote, and Steve Nelson for their assistance and comments. Early versions of this work were partially supported by the GOES Improved Product Assessment Program (GIMPAP) and funded by the NOAA/ NESDIS/Office of Systems Development. We would also like to thank Ashley Schaffer and Erin Pelham for comments on early drafts of manuscripts.

\section{REFERENCES}

Angel, J. R., and S. A. Isard, 1998: The frequency and intensity of Great Lake cyclones. J. Climate, 11, 61-71.
Browning, K. A., 2004: The sting at the end of the tail: Damaging winds associated with extratropical cyclones. Quart. J. Roy. Meteor. Soc., 130, 375-399.

Crupi, K. M., 2004: An anomalous non-convective high wind episode over upper Michigan. Natl. Wea. Dig., 28, 3-12.

Hultquist, T. R., M. R. Dutter, and D. J. Schwab, 2006: Reexamination of the 9-10 November 1975 "Edmund Fitzgerald" storm using today's technology. Bull. Amer. Meteor. Soc., 87, 607-622.

Iacopelli, A. J., and J. A. Knox, 2001: Mesoscale dynamics of the record-breaking 10 November 1998 mid-latitude cyclone: A satellite-based case study. Natl. Wea. Dig., 25, 33-42.

Klink, K., 2002: Trends and interannual variability of wind speed distributions in Minnesota. J. Climate, 15, 3311-3317.

Knox, J. A., 2004: Non-convective windstorms in the Midwest United States: Surface and satellite climatologies. Extended Abstracts, 22nd Severe Local Storms Conf., Hyannis, MA, Amer. Meteor. Soc., P5.3.

_ , and C. C. Schmidt, 2005: Using GOES total column ozone to diagnose stratospheric intrusions and nowcast non-convective cyclone windstorms: Methodology and initial results. Extended Abstracts, 13th Symp. on Meteorological Observation and Instrumentation, Savannah, GA, Amer. Meteor. Soc., 5.2.

Knox, P. N., 1996: Wind Atlas of Wisconsin. Wisconsin Geological and Natural History Survey, Bulletin 94, 47 pp.

Martin, J., 2000: An adjusted wind speed climatology for the southeastern United States. Ph.D. thesis, University of North Carolina at Chapel Hill, 327 pp. [Available from University of North Carolina Department of Geography, Saunders Hall, Campus Box 3220, Chapel Hill, NC 27599-3220.]

— , and C. E. Konrad II, 2006: Directional characteristics of potentially damaging wind gusts in the southeast United States. Phys. Geogr., 27, 155-169.

Niziol, T. A., and T. J. Paone, 2000: A climatology of non-convective high wind events in western New York state. NOAA Tech. Memo. NWS ER-91, 36 pp.

Pauley, P. M., N. L. Baker, and E. H. Barker, 1996: An observational study of the "Interstate 5" dust storm case. Bull. Amer. Meteor. Soc., 77, 693-720.

Richwien, B. A., 1980: Isallobaric contribution to a ship's sinking. Preprints, Eighth Conf. on Weather Forecasting and Analysis, Denver, CO, Amer. Meteor. Soc., 52-56.

Whittaker, L. M., and L. H. Horn, 1982: Atlas of Northern Hemisphere Extratropical Cyclone Activity, 1958-1977. Department of Meteorology, University of Wisconsin-Madison, $65 \mathrm{pp}$. 
Copyright of Journal of Climate is the property of American Meteorological Society and its content may not be copied or emailed to multiple sites or posted to a listserv without the copyright holder's express written permission. However, users may print, download, or email articles for individual use. 